\title{
Iniciativas de Responsabilidade Social Empresarial na Rede de Relações Empresa- Stakeholders como Fonte de Vantagem Relacional
}

\author{
Corporate Social Responsibility Initiatives in Relations Network Firm. \\ Stakeholders as Advantage Relationship Source
}

Natália Mary Oliveira de Souza ${ }^{I}$
Maria José da Silva Feitosa ${ }^{2}$
Carla Regina Pasa Gómez

\section{Resumo}

No intuito de garantir a sobrevivência e o diferencial competitivo no atual contexto de negócios, é imprescindível que as empresas desenvolvam parcerias com os stakeholders permeando os relacionamentos com iniciativas de RSE. Nesse contexto, o presente estudo tem como objetivo revisar um framework que integra RSE, relações "empresa-stakeholders" e vantagem competitiva. Para tanto, foi adotada uma revisão de literatura. Esta pesquisa justifica-se academicamente na medida em que aprimora uma proposição teórica estabelecida. Os resultados apontam que iniciativas de RSE no relacionamento entre a empresa e os seus stakeholders podem gerar uma vantagem relacional. Para pesquisas futuras, sugere-se a aplicação do modelo revisado.

Palavras-chave: Iniciativas de Responsabilidade Social Empresarial; Relações Empresa-Stakeholders; Vantagem Relacional.

\begin{abstract}
In order to ensure the survival and competitive positioning in the current business context, it is essential that companies develop partnerships with stakeholders, permeating relationships with CSR initiatives. In this context, this study aims to review a framework that integrates CSR, relations "firm-stakeholders" and competitive advantage. To this end, a literature review was performed. This research is justified academically the extent that enhances a theoretical proposition established. The results appoint that CSR initiatives in the relationship between the company and its stakeholders may generate a relational advantage. For future research, it is suggested the application of the revised model.
\end{abstract}

Keyword: Keywords: Corporate Social Responsibility Initiatives; Firm-Stakeholders Relationships; Relational Advantage.

\footnotetext{
1 natalia.o.souza@gmail.com, Brasil. Professora da Faculdade de Filosofia, Ciências e Letras de Caruaru - FAFICA. Mestre em Administração pela Universidade Federal de Pernambuco - UFPE. Av. Azevedo Coutinho, S/N, Petrópolis, CEP: 55030240 - Caruaru, PE - Brasil.

${ }^{2}$ mjsfeitosa@gmail.com, Brasil. Professora da Universidade Federal Rural de Pernambuco - UFRPE. Mestre em Administração pela Universidade Federal de Pernambuco - UFPE. Fazenda Saco, Zona Rural - Caixa Postal: 63, CEP: 56909-460 - Serra Talhada, PE - Brasil.

3 carlapasagomez@gmail.com, Brasil. Professora da Universidade Federal de Pernambuco - UFPE. Doutora em Engenharia de Produção pela Universidade Federal de Santa Catarina - UFSC. Av. Prof. Moraes Rego, 1235, Universitário, CEP: 50670-901 - Recife, PE - Brasil.
}

Recebido em 08.06.2012

Aprovado em 29.05.2014 


\section{Introdução}

O aumento das pressões sociais por uma atuação socioambiental responsável das empresas, atrelado à intensificação da competitividade, incitou nas organizações o interesse pelo desenvolvimento de práticas que atendam aos interesses dos stakeholders, ou seja, os públicos que, direta ou indiretamente, influenciam e são afetados pelas operações empresariais (FEITOSA; SOUZA; GÓMEZ, 2OI4).

Nessa perspectiva, o compromisso empresarial com a Responsabilidade Social Empresarial (RSE) passa a ser considerado um aspecto basilar no que tange ao desenvolvimento de parcerias e à obtenção de confiança com os públicos de interesse (MIRON, et al. 2OII). É justamente por isso que a RSE continua ganhando respaldo na esfera coorporativa, sendo um elemento primordial do diálogo das empresas com os seus stakeholders (BHATTACHARYA; KORSCHUN; SEN, 2OO9).

Assim sendo, as organizações devem preocupar-se em desenvolver parcerias permeando os relacionamentos com iniciativas de RSE. Dessa forma, pode-se obter uma solução "ganha-ganha", na qual tanto os objetivos de negócios (relacionados à melhoria de imagem e à obtenção de lucros), quanto os anseios dos stakeholders são alcançados, permitindo melhores resultados para ambas as partes (HAMANN, 2004).

Exemplificando, Sachdeva e Panfil (2008) afirmam que os agrupamentos de pequenas e médias empresas conseguem transformar os desafios de adotar práticas socialmente responsáveis em oportunidades de mercado, atuando de forma colaborativa. Agrupamentos são vistos como necessários para ampliar as práticas de RSE, apresentando resultados de competitividade e de desenvolvimento sustentável (ZADEK et al., 2003).

No entendimento de Castelo Branco e Rodrigues (2006) e Dyer e Singh (1998), relações positivas ou amigáveis entre empresa e seus públicos de interesse podem resultar no desenvolvimento de valiosos ativos intangíveis como, por exemplo, uma boa reputação no mercado, a qual pode ser considerada uma vantagem relacional. Esta, por sua vez, pode ser entendida como o benefício que uma organização pode obter em virtude um relacionamento sinérgico com os seus stakeholders.

A vantagem relacional é, portanto, um mecanismo capaz de gerar alguns dentre os vários ativos tangíveis e intangíveis necessários para se alcançar uma vantagem 
competitiva. Esta, por sua vez, decorre de um conjunto de recursos organizacionais internos (tangíveis e intangíveis) (BARNEY, I99I). Tal compreensão sobre vantagem competitiva permitiu a revisão do framework proposto por Feitosa, Souza e Gómez (20I4). No modelo proposto, as autoras alegam que a inserção dos princípios da RSE na rede de relações "empresa-stakeholders" gera uma vantagem competitiva. Segundo Feitosa, Souza e Gómez (2014):

Duas condições devem ser atendidas para que seja possível o alcance de vantagem competitiva através da RSE. São elas: (I) os princípios da RSE devem estar disseminados na rede de relacionamentos; (2) a empresa deve manter relações intensas e estreitas com os demais atores da rede. Atendendo essas duas condições, a vantagem competitiva é estabelecida, uma vez que os princípios da RSE, disseminados de forma intensiva na rede, farão parte de todas as relações empresastakeholders e, nesse caso, as referidas partes manterão relacionamentos saudáveis, decorrentes de um atendimento mútuo de interesses. (FEITOSA; SOUZA; GÓMEZ, 2014, p. 55).

Contudo, seguindo a linha de raciocínio apresentada por Barney (I99I), verificase uma limitação no modelo: considerar que apenas a intensidade de relacionamentos permeados por princípios de RSE é suficiente para alcançar uma vantagem competitiva, quando, na verdade, é apenas um dos meios para que ela (a vantagem competitiva) seja atingida.

Diante dessa lacuna, o presente estudo tem como objetivo revisar o Framework (que integra RSE, relações "empresa-stakeholders" e vantagem competitiva) proposto por Feitosa, Souza e Gómez (20I4). Para tanto, foi adotada uma revisão de literatura. Este estudo justifica-se academicamente na medida em que aprimora uma proposição teórica estabelecida.

Além deste conteúdo introdutório, o trabalho possui um embasamento teórico que aborda a visão relacional conforme Dyer e Singh (1998), bem como uma perspectiva sobre a análise de redes relacionais e, por último, a RSE nas relações "empresastakeholders" segundo Bhattacharya, Korschun e Sen (2009). Por conseguinte, verificase a reconfiguração do modelo proposto por Feitosa, Souza e Gómez (2OI4). Por fim, seguem as considerações finais e as referências. 


\section{A visão relacional conforme Dyer eSingh ( 1998$)$}

No campo da estratégia, são comuns estudos que procuram identificar as fontes de vantagem competitiva. Tais estudos estão enquadrados em duas visões de fontes de vantagem competitiva, quais sejam: a visão da estrutura da indústria e a visão baseada em recursos (RBV) da empresa. A primeira perspectiva, desenvolvida por Porter (I986), apregoa que retornos acima do normal são consequências da entrada de uma empresa em uma indústria com características estruturais favoráveis. Já a segunda, foca sua análise nos aspectos internos de uma organização, especificamente, nos recursos de uma empresa que permitem a vantagem competitiva (BARNEY, I99I; PENROSE, 2009; WERNERFELT, 1984).

No entanto, Dyer e Singh (I998) alertam que essas duas perspectivas negligenciam o fato de que as vantagens e desvantagens de uma empresa são muitas vezes ligadas às vantagens ou desvantagens da rede de relacionamentos da qual a empresa faz parte. Nessa perspectiva, a vantagem de relacionamento é definida como sendo os benefícios estratégicos obtidos em relação aos concorrentes no contexto de mercado, por meio da formação de parcerias em uma rede e da criação de conhecimento e sua relação com o resultado sinergético da atividade colaborativa que não pode ter sido adquirido por nenhuma firma atuando sozinha (CAO; ZHANG, 2OIO, DYER; SINGH, I998, DYER; SINGH; KALE, 2008).

A colaboração entre parceiros em uma rede de relacionamentos, como é o caso de uma cadeia de suprimentos, não é caracterizada somente por transações, mas contribui para o compartilhamento de informações e também para a criação do conhecimento de mercado que auxilia no alcance da vantagem competitiva sustentável (DING; HUANG, 2OIO; VACHON; KLASSEN, 2008). Nessa linha de raciocínio, entende-se que a vantagem de relacionamento constitui-se em fonte de rendas relacionais.

Rendas relacionais são lucros acima do normal gerados apenas por meio de contribuições idiossincráticas conjuntas dos parceiros específicos da aliança que não podem ser obtidos por uma empresa isolada. No contexto do relacionamento entre organizações, existem quatro fontes potenciais de vantagem competitiva: relação dos 
ativos específicos entre empresas, rotinas de compartilhamento de conhecimento, recursos e/ou capacidades complementares e governança eficaz (DYER; SINGH, I998).

A importância dos ativos específicos de uma empresa para obtenção de rendas relacionais é discutida na perspectiva da RBV. Grant (I99I), por exemplo, afirma que os recursos e capacidades da empresa são base para formulação da estratégia de uma organização sendo, portanto, a principal fonte de lucro. De acordo com Amit e Schoemaker (I993), uma empresa deve desenvolver ativos especializados para aumentar os lucros, uma vez que especialização de ativos é uma condição necessária para geração de rendas. Para esses autores, os ativos específicos desenvolvidos em conjunto com os integrantes de uma parceria possuem maior valor do que os ativos desenvolvidos individualmente por cada empresa.

Para Williamson (I979), existem três tipos de ativos específicos, a saber: local, físicos e humanos. A especificidade local refere-se à localização próxima das fábricas ou da produção dos parceiros da aliança para melhorar a coordenação e economizar nos custos de estoque e transporte. Já a especificidade de ativos físicos refere-se aos investimentos de capital em máquinas personalizadas, ferramentas, matrizes etc., permitindo a diferenciação, a qualidade e a integridade do produto e da empresa. Por último, a especificidade do ativo humano corresponde a transações específicas de knowhow acumulado por negociantes por meio de relações antigas, possibilitando a comunicação efetiva.

Sendo assim, o desempenho de uma empresa está ligado aos investimentos que esta, juntamente com seus parceiros, faz em ativos específicos locais, físicos e humanos. O investimento em tais ativos pode aumentar a qualidade dos produtos e a capacidade de absorção de informação para aprender com a experiência, além de reduzir o custo de transação. Corroborando essa afirmação, Dyer (I996) realizou um estudo empírico no qual evidenciou uma relação positiva entre o valor da cadeia de especificidade de ativos com a qualidade e desempenho da empresa.

O valor de um recurso especializado expõe o seu proprietário a um risco de oportunismo maior do que aquele que é detentor de um recurso generalizado. Desse modo, os negociantes que realizam transações devem se proteger contra os riscos de oportunismo, a partir da criação de salvaguardas. A necessidade de salvaguardar ocorre 
porque as partes podem ter interesses conflitantes, podendo se comportar de forma oportunista, aproveitando uma situação de assimetria de informação, ou seja, quando um agente participante da transação conhece informações que não estão disponíveis para outros agentes (BIJMAN, 2Oo6).

Complementado esse entendimento, Dyer (1996) afirma que as salvaguardas incluem acordos formais (contratos), e informais (confiança e reputação). Para esse autor, quanto maior a duração da salvaguarda para proteger contra o oportunismo e maior for o volume de transações entre os parceiros, maior será o potencial de gerar rendas relacionais, as quais podem ser compreendidas como os retornos financeiros advindos do relacionamento entre as empresas. De acordo com Dyer e Singh (1998) e Mursitama (2006), rendas relacionais são aquelas que pertencem à rede de relacionamentos.

A segunda fonte de rendas relacionais, sob a ótica relacional, é a rotina de partilha de conhecimento entre empresas. Segundo essa concepção, a colaboração e a troca de informação entre empresas permitem a aprendizagem organizacional, fundamental para o sucesso competitivo (FIGUEIREDO, 2004; FURTADO et al.,I994; KOGUT, I988). Para Figueiredo (2006), as ligações interorganizacionais são fontes para a construção e desenvolvimento de capacidade tecnológica e, consequentemente, de inovação. Nesse sentido, as parcerias de uma empresa compreendem uma importante fonte de ideias e informações que resultam em melhor desempenho.

Dyer e Singh (1998) acreditam que os parceiros da rede podem gerar rendas por meio do desenvolvimento de rotinas superiores de partilha de conhecimentos entre empresas. De acordo com Grant (I996), a partilha de conhecimento entre firmas, a partir da interação e colaboração entre firmas, permite a transferência, recombinação ou criação de conhecimento especializado. O conhecimento especializado é, então, trocado e imitado a partir das alianças (KOGUT, I988).

A capacidade de explorar as fontes de conhecimento varia em função da capacidade de absorção da empresa. Cohen e Levinthal (I990) argumentam que a capacidade de absorção de uma empresa em reconhecer o valor das informações, assimilá-las e aplicá-las para fins comerciais é fundamental para as suas capacidades inovadoras. Segundo os referidos autores, tal capacidade é aquela que permite explorar o conhecimento externo. A capacidade de avaliar e utilizar o conhecimento externo varia 
consideravelmente em função do nível de conhecimento prévio relacionado. Sendo assim, a capacidade de absorção da empresa tenderá a se desenvolver cumulativamente, envolvendo não apenas a aquisição ou assimilação de informações por uma organização, mas a capacidade da empresa para organizá-la.

A capacidade dos parceiros de aliança para gerar rendas por meio do compartilhamento do conhecimento depende de incentivos para que eles sejam transparentes, objetivando a transferência de conhecimento. Assim, quanto maior for o alinhamento de incentivos por parceiros da aliança em promover a transferência e reciprocidade, maior será o potencial para gerar rendas relacionais por meio da partilha de conhecimento (DYER; SINGH, I998). Como forma de gerar rendas relacionais, os parceiros da rede devem possuir recursos complementares, bem como uma capacidade relacional (ÄYVÄRI; MÖLLER, 2008). Essa capacidade é compreendida no contexto de formação de alianças e refere-se à vontade e habilidade da empresa para formação de parcerias.

Uma terceira fonte de rendas relacionais é a doação de recursos complementares de um parceiro da aliança. Dyer e Singh (1998) definem doação de recursos complementares como aqueles distintivos de parceiros da aliança que, quando combinados com os de outros parceiros, resultam em recursos mais valiosos, raros e difíceis de imitar do que aqueles individuais, aumentado, assim, o potencial para gerar rendas relacionais.

Ainda segundo esses autores, a habilidade de uma empresa para identificar parceiros com recursos complementares ocorre em função de alguns aspectos, a saber: do nível de experiência da empresa, no que tange ao gerenciamento da aliança; das pesquisas internas que buscam identificar e avaliar potenciais parceiros da aliança, bem como monitorar e coordenar suas atuais alianças; e da extensão pela qual a empresa tem acesso a informações exatas e oportunas (DYER; SINGH, I998).

Quanto ao terceiro aspecto que influencia a habilidade de uma empresa em identificar parceiros com recursos complementares, empresas com uma posição central em uma rede de relacionamentos exercem importante papel. Tais empresas têm acesso privilegiado às informações que circulam na rede e podem exercer poder sobre as demais empresas da rede (GRANOVETTER, I985; TOMAÉL; MARTELETO, 2OO6). 
Além de desenvolver habilidades para identificar um parceiro potencial, a empresa deve ser capaz de utilizar e se beneficiar dos recursos estratégicos complementares. Segundo Doz (I996), tal habilidade é dependente da compatibilidade dos processos, sistemas e cultura organizacional.

Por último, a quarta fonte de rendas relacionais é a governança efetiva, a qual por sua vez, contribui para que aqueles que desenvolvem parcerias possam, a médio e longo prazo, manter um relacionamento dentro de um contexto específico (WILLIAMSON, I985). As parcerias podem ser formadas a partir de dois tipos de governança: formal e informal.

A primeira refere-se às relações contratuais estabelecidas em um ambiente de incerteza e a preocupação com o oportunismo (WILLIAMSON, I99I). Este tipo de governança depende de terceiros para execução dos acordos e eleva os custos de transação.

Já a governança informal, menos onerosa, se dá por meio da confiança obtida por meio de uma relação direta (face a face) e da reputação (LARSON, I992). A reputação de uma empresa no mercado é um importante fator para se avaliar uma parceria, uma vez que se evita relacionar com empresas de má reputação (MACAULAY, I963).

Nessa perspectiva, Madhok (1997) atenta para o fato de que o uso de mecanismos informais de governança, como a confiança e reputação, permitem uma maior interação entre os parceiros da rede da aliança. Dessa forma, aumenta-se a partilha de informações e, consequentemente, desenvolvem-se relações duradouras, além de diminuir o custo de transação.

Nesse contexto, Macaulay (I963) argumenta que os empresários dificilmente recorrem a extensos contratos. Para o autor, contratos detalhados podem influenciar negativamente as relações de troca entre unidades de negócio. Além disso, contratos detalhados poderão acarretar no atraso dos resultados pretendidos pela parceria e aumentar os custos de transação. No entanto, o autor apregoa que transações importantes, que não estão no curso normal dos negócios, são tratadas por um contrato detalhado.

Uma vez explanadas as quatro fontes de rendas relacionais que podem ocorrer no contexto do relacionamento entre as organizações constata-se, com base na visão 
relacional, a importância do desenvolvimento de relações de parcerias de uma empresa ou grupo de empresas com os mais diversos atores sociais.

\section{Uma perspectiva sobre a análise de redes relacionais}

As empresas desenvolvem relações com seus stakeholders caracterizando uma rede de influências, em que são comuns entre os seus participantes as trocas de materiais, informações, etc. Nesse sentido, Silva e Coser (2006) afirmam que essas redes incluem outras organizações, assumindo grande importância para os envolvidos, visto que possibilitam a regulação das interdependências transacionais mais complexas e apresentam movimentos para a cooperação e competição.

Nessa perspectiva, as redes correspondem a um grupo de atores que se relacionam e se agrupam em torno de objetivos compartilhados, sendo necessário, para alcançá-los, a existência de fluxos de informações. Nessa linha de entendimento, Silva e Coser (2006) definem rede como um conjunto de nós interligados por relacionamentos, os quais podem ser de caráter econômico e social.

Diante da definição apresentada, verificam-se nas redes três elementos básicos, quais sejam: nós, relações e fluxos. Para Alejandro e Norman (2005), os nós são atores sociais (pessoas ou organizações) que se agrupam em torno de uma finalidade. As relações, por sua vez, são os laços ou vínculos que conectam os atores. Por último, os fluxos dizem respeito à direção das relações entre os nós.

O estudo de redes ganhou ampliação a partir do momento que o trabalho pessoal em redes foi percebido como uma ferramenta organizacional. Nesse momento, a teoria de rede passou a exigir dados empíricos complementares, possibilitados pela análise de redes (MARTELETO, 2OOI).

A análise de redes pode ser aplicada no estudo de diferentes situações e questões sociais, permitindo tanto explicar fenômenos presentes em uma rede, quanto identificar as influências que a estrutura da rede exerce sobre as relações (MARTELETO, 2OOI).

Nessa perspectiva, Souza e Quandt (2007) assumem que dois indicadores contribuem para a análise das redes, quais sejam: densidade e a centralidade. Ambas as medidas permitem diferenciar as relações adotadas pelos atores na rede. A densidade possibilita considerações sobre a estrutura da rede. De outro modo, a densidade é uma 
característica de toda a rede, podendo ser calculada como a razão do número de relacionamentos observáveis (existentes), comparando com o número total de relações possíveis (se todos os membros possuíssem relações com todos os demais atores da rede) (MASQUIETTO; SACOMANO NETO; GIULIANI, 2OIO; PECI, I999; ROWLEY, I997).

Quando as relações numa rede se tornam mais densas, a tendência é que a comunicação na rede se torne mais eficiente e, como consequência, há maior difusão de informações, normas, valores e padrões de comportamentos entre os nós (SOUZA; QUANDT, 2007). Dessa forma, quanto maior a densidade das relações, maior será a probabilidade de que os stakeholders se mobilizem para influenciar o comportamento da organização focal, buscando adequar o comportamento desta aos objetivos da rede (ROWLEY; MOLDOVEANU, 2OO3).

Seguindo a linha de raciocínio das consequências da densidade, Peci (I999) afirma que redes densas podem possibilitar relações colaborativas e, em alguns casos, permitem adquirir capacidades que facilitam a adaptação às mudanças (flexibilidade). Por outra parte, redes densas possibilitam a confiança entre os atores na rede, balizado assim o comportamento oportunista destes (GILSING et al., 2008).

No que diz respeito à centralidade, pode-se afirmar que essa ferramenta permite identificar a posição dos atores na rede ou, como afirmam Troccoli e Macedo-Soares (2004, p. 59), a “participação em número significativo de relacionamentos”. Peci (I999), Souza e Quandt (2007) destacam que a centralidade permite avaliar a habilidade de um determinado ator para controlar o fluxo de informação ao longo da rede. Para Rossoni e Guarido Filho (2007), a centralidade pode apontar para a importância e poder de um ator em relação aos demais atores, de modo que quanto mais central um nó em uma rede, maior a sua importância e seu poder em relação aos outros nós.

A análise de redes utiliza três tipos de centralidade para definir a posição de uma organização na rede, a saber: centralidades de grau, de intermediação e de proximidade (PECI, I999; TOMAÉL; MARTELETO, 2006). Segundo Wasserman e Faust (I994) e Martins et al. (2009), a centralidade de grau permite identificar o número de vínculos diretos que um ator mantém em uma rede. 
Nesse contexto, Cox, Melo e Régis (2009) argumentam que a alta centralidade de grau permite que o ator central passe a ser enxergado por si mesmo e pelos outros atores como sendo o maior canal de comunicação da rede, dado que mantém contato direto com os vários outros nós. Dessa forma, a alta centralidade de grau permite que o ator central tenha acesso a diversas fontes alternativas de informações e recursos (ROWLEY, 1997). Em contrapartida, a baixa centralidade de grau de um ator ocasiona o isolamento, a percepção de ator periférico com participação passiva no processo de comunicação.

Em se tratando da centralidade de intermediação, Tomael e Marteleto (2006) afirmam que o nó que apresenta uma alta centralidade desse tipo tem a função de interligar atores periféricos, ou seja, tal nó pode ser considerado meio para alcançar e coligar outros atores. Assim sendo, o nó detentor dessa centralidade possui poder e controla os atores periféricos, uma vez que estes dependem do nó com elevado poder de intermediação para realizar conexões com outros atores (COX; MELO; RÉGIS, 2009).

Por último, a centralidade de proximidade representa independência, pois quanto maior ela é, menor será a necessidade de um ator possuir intermediários para desenvolver comunicações com outros atores (MASQUIETTO; SACOMANO NETO; GIULIANI, 20IO). Nessa perspectiva, Tomaél e Marteleto (2006) argumentam que essa independência está relacionada à proximidade que um nó mantém em relação a todos os outros nós.

A densidade e a centralidade são comuns em estudos empíricos que procuram estudar as relações entre atores sociais em redes interorganizacionais. Czepiel (I974) citado por Freeman (1979), por exemplo, aplicou os conceitos em uma rede densa da indústria do aço. Dentre os resultados do estudo, o autor identificou que as empresas siderúrgicas mais centrais possuíam um rico canal de comunicação, além de obter vantagem tecnológica sobre as demais empresas.

Outra contribuição empírica relevante pode ser observada no estudo de Silva e Coser (2006), os quais avaliaram uma rede agroindustrial do estado de Santa Catarina. Os resultados do estudo apontam a existência de uma organização central que gerencia todo o ciclo produtivo e controla outras organizações na rede. 
Por fim, destaca-se o trabalho de Souza, Primo e Correa (2OII) que estudaram o Porto Digital localizado no Recife, capital do Estado de Pernambuco. Conforme tais autores, o Porto se configura em uma rede composta por organizações de tecnologia da informação e comunicação. Existe uma proximidade geográfica entre a maior parte dos atores da rede, permitindo a troca de informação entre estes. Na rede do Porto Digital foram identificadas empresas centrais, as quais são reconhecidas como "âncoras", possuindo status e boa reputação reconhecidos pelos demais integrantes da rede e pelo público externo.

Nesse contexto, é importante ressaltar que a interligação entre densidade de rede e centralidade em uma organização acarreta em distintas estruturas de rede, as quais interferem nas relações de poder existentes entre as empresas e seus públicos de interesse (ROWLEY, 1997). Este autor investigou o referido vínculo conceitual, propondo um modelo ilustrado no Quadro oI, a seguir.

Quadro oı: Estrutura de influência e respostas das organizações às pressões dos stakeholders.

\begin{tabular}{|l|l|l|l|}
\hline Papel da organização & \multicolumn{1}{|c|}{ Densidade } & Centralidade & \multicolumn{1}{c|}{ Descrição (características) } \\
\hline Conciliador & Alta & Alta & $\begin{array}{l}\text { A organização se tornará conciliadora, tentando se } \\
\text { equilibrar, pacificar e negociar com seus } \\
\text { stakeholders influentes uma posição satisfatória. }\end{array}$ \\
\hline Comandante & Baixa & $\begin{array}{l}\text { A organização consegue dominar e controlar os } \\
\text { fluxos de informação, as trocas de recursos na } \\
\text { rede e constituir normas compartilhadas. Essa } \\
\text { organização consegue deter recursos raros e } \\
\text { informações importantes, permitindo um alto } \\
\text { poder de negociação sobre os stakeholders. }\end{array}$ \\
\hline Subordinado & Alta & $\begin{array}{l}\text { A organização adota uma posição periférica, } \\
\text { sendo influenciada e subordinada aos } \\
\text { stakeholders. A organização aceita as normas e } \\
\text { age de acordo com as exigências dos } \\
\text { dtakeholders. Nessa relação, os stakeholders } \\
\text { possuem o poder de negociação em relação à } \\
\text { empresa. }\end{array}$ \\
\hline Solitário & Alta & Baixa & $\begin{array}{l}\text { A organização oculta suas atividades, dissimula } \\
\text { conduta e não atende às demandas e } \\
\text { exigências dos stakeholders. Nessa relação (ou } \\
\text { ausência de relação), a empresa não sobrevive. }\end{array}$ \\
\hline
\end{tabular}

Fonte: Adaptado de Rowley (I997)

A partir do Quadro or observa-se que em uma rede densa todos os participantes têm acesso às informações difundidas na rede. Dessa forma, o conhecimento perde a 
condição de novidade. Nesse sentido, a densidade alta possibilita que os stakeholders se mobilizem para pressionar e influenciar a organização para atender as suas necessidades. Caso a centralidade da organização focal seja baixa a organização se torna incapaz de influenciar o processo de troca de informações, subordinando-se as exigências dos stakeholders (a organização exerce o papel de subordinada) (ROWLEY; MOLDOVEANU, 2OO3).

Segundo Gilsing et al. (2008), o problema da falta de novidade dos conhecimentos em uma rede densa pode ser compensando pela centralidade de intermediação, permitindo que a organização busque novas oportunidades, novos conhecimentos e absorva-os. Por meio das informações contidas no Quadro oI, pode-se compreender que a organização central, em uma rede densa, procura negociar as exigências dos stakeholders, buscando uma relação "ganha-ganha" (a organização exerce o papel de conciliadora). As informações na rede são compartilhadas, contudo, a organização central poderá obter as informações em primeira mão, antes dos demais atores, decidindo, com agilidade, o que fazer com elas.

Por outro lado, pela discussão anteriormente apresentada sobre densidade, entende-se que uma rede pouco densa acarreta em atores dispersos, em que a comunicação e as informações são eventuais e, consequentemente, o conhecimento é pouco difundido. Nesse caso, a probabilidade dos stakeholders se mobilizarem para influenciar as organizações é baixa, uma vez que não trocam informações entre si e, dessa forma, não compartilham as suas necessidades.

Diante dessa situação, um nó central pode obter benefícios nessa rede, uma vez que dominará o conhecimento existente, podendo ser caracterizado como um importante canal de comunicação, que controla o diálogo entre os atores e garante a independência dos demais atores. Em contrapartida, um ator com baixa centralidade em uma rede pouco densa se isola dos demais atores e não desenvolve relações com estes, assemelhando-se a um sistema fechado (que não interage com o ambiente externo) e, dessa forma, acaba extinguindo-se no ambiente competitivo.

Independente do poder de influência que os stakeholders possuem, as empresas devem constantemente monitorá-los, a fim de obter informações relevantes, descobrir suas aspirações e os fatores que poderão impactar nas ações empresariais (FEITOSA; 
SOUZA; GÓMEZ, 20I4). Acompanhar os stakeholders torna-se relevante para que as empresas compreendam as necessidades e os anseios destes públicos, a partir do desenvolvendo de parcerias sólidas.

Nos últimos anos as expectativas dos stakeholders têm sido fortemente influenciadas pela problemática socioambiental instalada. Em função disso, as empresas empenham mecanismos de ação que, concomitantemente, suprem as demandas ambientais e elevam o desempenho empresarial no mercado, o qual passa a ser impulsionado, por exemplo, pela boa imagem empresarial (FEITOSA; SOUZA; GÓMEZ, 20I4). Esta, por sua vez, pode ser adquirida por meio de iniciativas de RSE nas relações "empresa-stakeholders".

\section{RSE nas relações empresa-stakeholders segundo Bhattacharya, Korschun e Sen} (2009)

Pressões advindas do ambiente externo têm despertado nas empresas a necessidade de aderir em sua missão e em seus processos as diretrizes postuladas pela Responsabilidade Social Empresarial (RSE), a qual pode ser entendida como o posicionamento ético, transparente e responsável da empresa para com seus stakeholders, buscando alinhar aspectos de ordem econômica, social e ambiental (COMMISSION OF THE EUROPEAN COMMUNITIES, 2002; INSTITUTO ETHOS, 2OIO; LEANDRO; RABELO, 2OII; RAMACHANDRAN, 2OIO).

Para Bhattacharya, Korschun e Sen (2009), as iniciativas de RSE nos negócios podem beneficiar tanto a organização quanto as partes interessadas. A empresa que tem suas iniciativas percebidas e positivamente reconhecidas, obtém um stakeholder que se identifica com seus valores e princípios, que demonstra confiança, comprometimento e satisfação com as suas iniciativas.

Para os públicos de interesse, tais iniciativas geram benefícios funcionais, isto é, tangíveis e diretamente relacionados às características do produto ou serviço que a empresa oferece; psicossociais, ou seja, concernentes ao bem estar psicológico e sociológico das partes interessadas e, por último, atributos capazes de afirmar os valores e princípios dos indivíduos, sendo estes de caráter abstrato (BHATTACHARYA; KORSCHUN; SEN, 2009). 
Para explicitar melhor estes tipos de benefício, verificou-se um estudo de Bhattacharya, Du e Sen (2005) citados por Bhattacharya, Korschun e Sen (2009). Estes autores investigaram uma companhia que desenvolveu um programa de RSE para crianças, as quais, sendo beneficiárias da iniciativa, receberam benefícios funcionais notáveis, tais como dentes saudáveis e limpos. As crianças, com sorrisos bonitos, sentiram uma maior aceitação social de seus pares, o que resultou em conectividade social e autoestima por parte destas.

Os consumidores em geral, apesar de não obterem nenhum benefício funcional no exemplo mencionado, ao perceberem as iniciativas, passaram a comprar os produtos da marca que patrocinou a iniciativa (no intuito de ajudar as crianças necessitadas), atitude esta que proporcionou uma sensação de bem estar e contentamento para este consumidor (benefício psicossocial/que afirma os valores individuais) (BHATTACHARYA; DU; SEM, 2005 apud BHATTACHARYA, KORSCHUN; SEM, 2009).

Conforme estes mesmos autores, os investidores obtêm benefícios funcionais (pelo retorno das ações e menor risco), os quais podem resultar em benefícios psicossociais e desenvolvimento profissional, que, por sua vez, como no caso de outros stakeholders, contribuem para um sentido de realização e autoestima. Por último, no exemplo, a partir das iniciativas de RSE, os funcionários da empresa que adota as iniciativas recebem inúmeros benefícios funcionais e psicossociais, a saber: integração entre vida e trabalho, autoexpressão no trabalho etc.

Contudo, tais iniciativas devem, em um primeiro momento, gerar retornos para os públicos de interesse para que, posteriormente, possam beneficiar a companhia. $\mathrm{Ou}$ seja, o benefício obtido pela empresa variará em função dos retornos percebidos pelos stakeholders na relação que estes mantêm com a organização. Citando Waddock e Smith (2000), Bhattacharya, Korschun e Sen (2009) afirmam que iniciativas de RSE são bem sucedidas em gerar retornos para a empresa, na medida em que elas fomentam relações fortes e duradouras com os stakeholders.

A natureza e a extensão dos benefícios gerados determinam a qualidade da relação empresa-stakeholder, ou seja, a força do relacionamento entre ambas as partes (BHATTACHARYA; KORSCHUN; SEN, 2009). Nesta perspectiva, estes mesmos 
autores assumem que a qualidade da já referida relação é influenciada pelo grau no qual os stakeholders conseguem obter benefícios a partir da atividade de RSE, bem como a natureza destes benefícios. Quando os stakeholders aprendem sobre ou participam de iniciativas de RSE patrocinadas por uma companhia, iniciam-se trocas recíprocas de informações e ações, as quais podem fortalecer os laços entre os envolvidos.

Em geral, quando os públicos de interesse desenvolvem uma relação forte com a empresa, em virtude dos benefícios que a RSE proporciona, eles estarão propensos a engajar outras partes interessadas em um comportamento cooperativo com a organização. Contudo, é importante ressaltar que os benefícios positivos da RSE são ampliados no caso das organizações que têm boa reputação. Empresas com uma reputação fraca ou duvidosa têm reduzidas as vantagens decorrentes da RSE, pois os stakeholders suspeitam dos motivos que fazem com que uma empresa patrocine iniciativas de Responsabilidade Social Empresarial, como é o caso da indústria de tabaco (BHATTACHARYA; KORSCHUN; SEN, 2O09).

Assim sendo, entende-se que a reputação positiva tanto é aspecto fundamental para que os stakeholders se aproximem da companhia, quanto é um elemento construído a partir de uma boa relação com as partes interessadas. Na ótica de Castelo Branco e Rodrigues (2006) e Dyer e Singh (1998), esta aproximação empresa-stakeholders permite o desenvolvimento e/ou fortalecimento de valiosos ativos intangíveis (boa reputação, conhecimento etc.), que estão na lista dos ativos necessários ao alcance da vantagem competitiva no mercado.

A discussão e as teorias apresentadas nesta revisão bibliográfica viabilizaram o ajustamento e incremento do modelo proposto por Feitosa, Souza e Gómez (2OI4), o qual é resultante da integração entre as teorias que tratam da Responsabilidade Social Empresarial, da análise da rede de relações "empresa-stakeholders" e a vantagem competitiva.

Apesar de apresentar uma discussão teórica relevante e já estabelecida, o estudo realizado por estas autoras apresenta uma limitação, a qual se revela quando assumem que para uma empresa obter uma vantagem competitiva por meio da RSE basta que ela (a organização) atenda a duas condições: (I) dissemine os princípios da RSE na rede de 
relacionamento que mantém como os seus stakeholders e, (2) que as relações mantidas entre ambas as partes sejam intensas e estreitas.

Sabendo-se que a vantagem competitiva, segundo Barney (I99I), é oriunda de um conjunto de ativos (tangíveis e intangíveis) e não apenas da vantagem de relacionamento da empresa com seus públicos de interesse, verifica-se a necessidade de revisão do modelo teórico proposto por Feitosa, Souza e Gómez (2OI4).

\section{Revisão do modelo proposto por Feitosa, Souza e Gómez (20I4)}

Como dito anteriormente, o modelo criado por Feitosa, Souza e Gómez (20I4) explica como a disseminação dos princípios de RSE em uma rede de relacionamentos "empresa-stakeholders" pode contribuir para o alcance de vantagem de competitiva. As principais considerações do modelo proposto pelas autoras estão descritos no Quadro $\mathrm{O} 2$, a seguir.

Quadro 02: Integrando RSE, relações "empresa-stakeholders" e vantagem competitiva

\begin{tabular}{|c|c|c|}
\hline Tipo de vantagem competitiva & Densidade e centralidade & Descrição \\
\hline Vantagem competitiva Total & $\begin{array}{l}\text { A rede é densa e a empresa } \\
\text { possui alta centralidade. }\end{array}$ & $\begin{array}{l}\text { As empresas centrais, nesse caso, são } \\
\text { caracterizadas como conciliadoras, procuram } \\
\text { negociar com os stakeholders de forma que } \\
\text { ambos sejam favorecidos. Esta relação } \\
\text { permite a confiabilidade e fidelização por parte } \\
\text { do cliente. }\end{array}$ \\
\hline Vantagem competitiva Parcial & $\begin{array}{l}\text { A empresa possui alta } \\
\text { centralidade, mas a } \\
\text { densidade da rede é baixa. }\end{array}$ & $\begin{array}{l}\text { A empresa, caracterizada como comandante, } \\
\text { pode influenciar o fluxo de informações e as } \\
\text { normas compartilhadas em uma rede, } \\
\text { podendo optar por não adotar as práticas de } \\
\text { RSE nas relações com os stakeholders. } \\
\text { Contudo, essa vantagem poderá acabar caso } \\
\text { surja novos concorrentes. }\end{array}$ \\
\hline Desvantagem competitiva Parcial & $\begin{array}{lr}\text { Empresas com baixa } \\
\text { centralidade, em redes } \\
\text { altamente densas. }\end{array}$ & $\begin{array}{l}\text { As empresas são subordinadas às normas e } \\
\text { expectativas impostas pelos stakeholders. } \\
\text { Todavia, a situação de subordinada não é } \\
\text { permanente. }\end{array}$ \\
\hline Desvantagem competitiva Total & $\begin{array}{l}\text { Empresas com baixa } \\
\text { centralidade, presentes em } \\
\text { redes com baixa densidade. }\end{array}$ & $\begin{array}{l}\text { Este tipo de organização, caracterizada por } \\
\text { ser solitária não sobreviverá por muito tempo, } \\
\text { possuindo, então, desvantagem competitiva } \\
\text { total. }\end{array}$ \\
\hline
\end{tabular}

Fonte: Feitosa, Souza e Gómez (2014)

Revista Administração em Diálogo ISSN 2178-0080

Programa de Estudos Pós-Graduados em Administração Pontifícia Universidade Católica de São Paulo 
Contudo, seguindo a definição de vantagem competitiva proposta por Barney (I99I), verifica-se que o modelo é limitado ao considerar que apenas a intensidade de relacionamentos permeados por princípios de RSE geram uma vantagem competitiva. O que o ocorre, no entanto, é que tais relacionamentos são um ingrediente necessário para que ela (a vantagem competitiva) seja atingida.

Antes de apresentar a revisão do modelo, torna-se necessário realizar algumas considerações. Em primeiro lugar, considera-se, neste estudo, que os stakeholders valorizam práticas de responsabilidade social adotadas pelas empresas. Faz-se ainda uma ressalva: os estudos de Darnall, Henriques e Sadorsky (20IO) indicam que existe uma relação positiva entre as pressões dos stakeholders e a adoção de práticas ambientais proativas, ou seja, os stakeholders valorizam empresas que desenvolvem práticas ambientais voluntárias.

A segunda consideração diz respeito aos atributos dos stakeholders. Segundo Mitchel, Agle e Wood (1997), estes públicos podem possuir um ou mais de um dos seguintes atributos: poder para influenciar uma empresa; legitimidade do relacionamento com a empresa; urgência de reivindicação da parte interessada na empresa. Os atributos isolados não implicam em uma mobilização de influência dos stakeholders. Caso estes possuam pelo menos poder e urgência, existirá mobilização para influenciar os stakeholders.

No presente estudo, considera-se que apenas poder e urgência (exigência para que as empresas adotem a responsabilidade social) não garantem a mobilização dos stakeholders. Para que a mobilização ocorra, é necessário que os stakeholders possuam recursos para agir e que fatores externos não impeçam a ação.

Por fim, é preciso esclarecer o entendimento da vantagem relacional. $\mathrm{Na}$ literatura encontramos estudos que afirmam a existência de fontes de vantagem competitiva, as quais já foram discutidas anteriormente. Porter (I986) utiliza a visão da estrutura da indústria, já autores como Barney (I99I) e Penrose (2009) defendem a visão baseada em recursos (RBV) da empresa para explicar a vantagem competitiva. Dyer e Singh (I998) afirmam que além dos fatores apresentados, o relacionamento pode ser tido como uma fonte de vantagem competitiva. Neste estudo, considera-se que os 
relacionamentos podem gerar benefícios para a empresa, como, por exemplo, poder, status, informação, conhecimento e recursos valiosos.

Para obter tais benefícios, a empresa deve aproveitar as oportunidades de maneira legítima e nenhum fator externo poderá impedir o relacionamento da empresa com os stakeholders. A consequência desse relacionamento poderá ser um desempenho superior em relação aos concorrentes. A vantagem relacional, portanto, estaria vinculada à exploração das oportunidades que a empresa pode obter a partir dos relacionamentos que ela desenvolve na rede.

Diante do exposto, entende-se que as iniciativas de RSE, a partir do momento que são valorizadas pelos stakeholders, podem gerar retornos para a empresa, por meio da formação de relações fortes e duradouras entre esta e as partes interessadas. Nessa perspectiva, ainda que os stakeholders possuam legitimidade, poder e urgência para exigir ações socialmente responsáveis, tende a ser valorizada a empresa que apresenta esse tipo de comportamento de maneira voluntária.

Dessa forma, as empresas que atendem as exigências socioambientais de modo voluntário podem usufruir da vantagem relacional, a partir do compartilhamento de informações e da criação do conhecimento de mercado, os quais, dentre outros elementos, podem auxiliar no alcance da vantagem competitiva.

Por outro lado, uma situação oposta estaria relacionada com o fato das empresas não se preocuparem em satisfazer a urgência dos stakeholders em termos de RSE, caso esses valorizem tais práticas, bem como com o fato dos stakeholders não interagirem entre si. As empresas, nesse caso, caracterizam-se pelo isolamento e acabam sucumbindo no mercado.

Com base no exposto, o modelo proposto por Feitosa, Souza e Gómez (2014) foi revisado, resultando em uma nova configuração, a qual pode ser visualizada na Figura oI. A partir da relação de confiança, proximidade, troca de conhecimento, as empresas da rede podem criar uma estratégia de Responsabilidade Social Empresarial valiosa, rara e difícil de imitar, diferentemente do que ocorreria se a estratégia de RSE fosse desenvolvida isoladamente.

É importante salientar que permanecem semelhantes entre o modelo anterior e o revisado (Figura oI) as relações entre as medidas de centralidade e densidade. Contudo, 
a inovação teórica do presente consiste em identificar a vantagem relacional como sendo um dos ativos que podem levar à vantagem competitiva.

Figuraor: Modelo integrando RSE, relações "empresa-stakeholders" e vantagem relacional

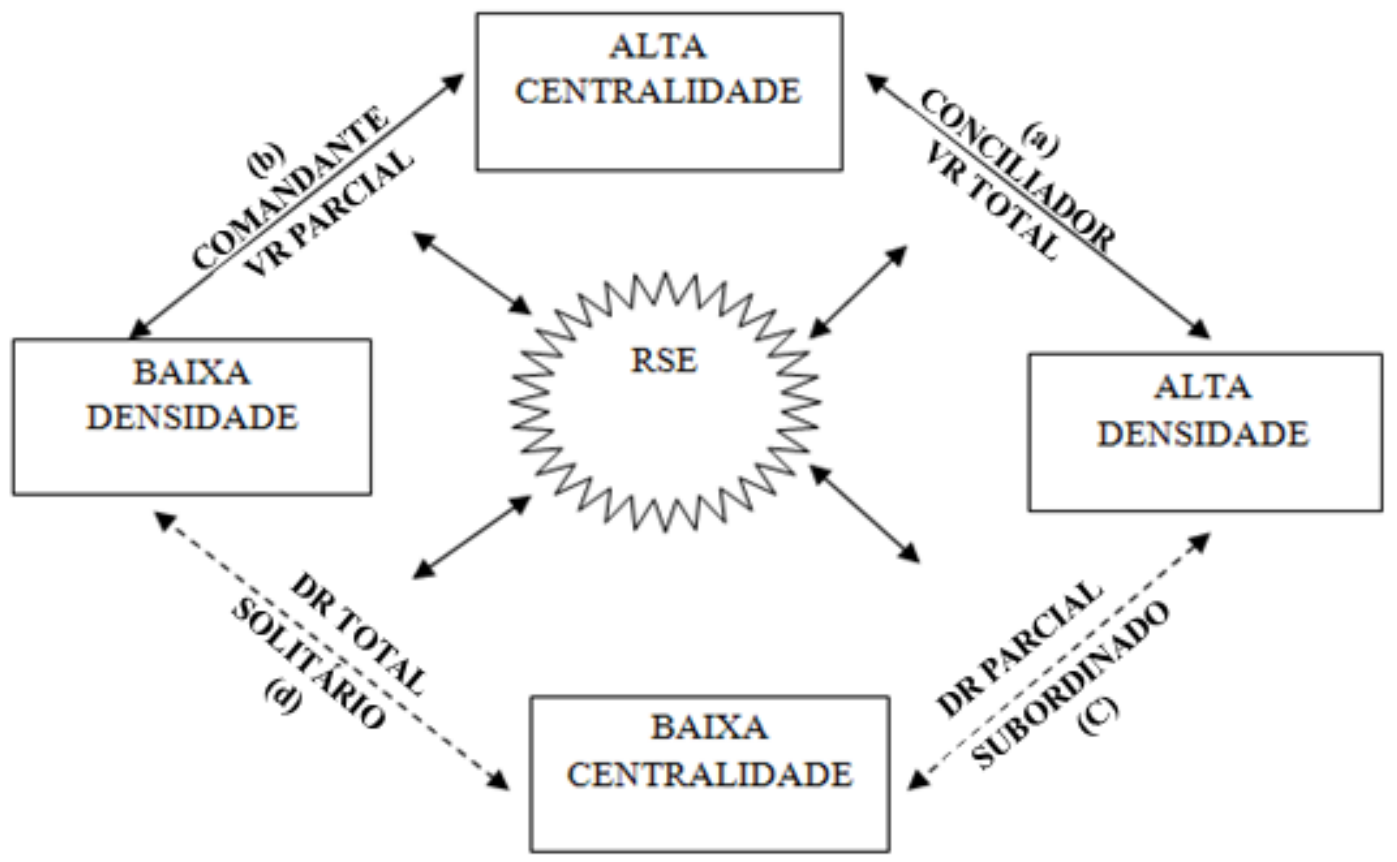

VR - Vantagem Relacional

DR - Desvantagem Relacional

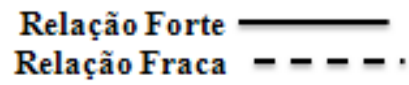

Fonte: Adaptado de Feitosa, Souza e Gómez (2014)

Com base na Figura oI, a situação (a), na qual a vantagem relacional é total, envolve tanto stakeholders que coordenam seus esforços para demandar das empresas práticas de RSE, quanto empresas vislumbradas como conciliadoras, as quais procuram negociar com os stakeholders de forma que ambas as partes sejam favorecidas. Nessa relação observa-se o aumento da confiança entre a organização e os públicos de interesse, possibilitando o surgimento de um valor intrínseco. Este, em sendo permeado por princípios da RSE, garante a fidelidade dos stakeholders e acarreta em uma vantagem relacional total. São relações, portanto, duradoras, nas quais a empresa constrói uma imagem forte e honesta perante os demais atores da rede, usufruindo de rendas relacionais. considerada comandante, tendo em vista que influencia o fluxo de informações e as 
normas compartilhadas na rede, optando ou não pela adoção das práticas de RSE nas relações com os seus stakeholders. Nesse caso, a relação existente entre as partes mencionadas não envolverá confiança e fidelidade, uma vez que, nesse caso, a relação é predominantemente unilateral (partindo da empresa para os stakeholders), resultando, assim, em uma vantagem relacional parcial. Em uma perspectiva de longo prazo, outra organização que empregue os princípios de RSE, pode passar a integrar esta rede, tornando-se central e alcançando, portanto, vantagem de relacionamento.

Em relação à situação c, que ilustra a desvantagem relacional parcial, as empresas adotam uma posição de subordinadas aos seus stakeholders, tendo em vista que se adéquam às pressões e exigências destes. Contudo, essa relação pode sofrer alterações positivas favorecendo a empresa na medida em que a referida passa a desenvolver práticas voluntárias de RSE, adquirindo respeito e confiabilidade por parte dos stakeholders.

Por último, a desvantagem relacional total (caso d), ocorrerá quando a empresa, visualizada como solitária, não atender as solicitações de iniciativas de RSE dos stakeholders. Além disso, estará nessa situação a organização que estiver alocada em uma rede pouco densa, na qual não existe o compartilhamento das informações e os relacionamentos são considerados frágeis.

A relação entre densidade, centralidade e vantagem relacional encontra-se resumida no Quadro o3, a seguir.

Quadro o3: Relação entre densidade, centralidade e vantagem relacional

\begin{tabular}{|c|c|c|}
\hline Situação da empresa & Situação da rede & Tipo de vantagem \\
\hline Alta centralidade & Alta densidade & Vantagem relacional total \\
\hline Alta centralidade & Baixa densidade & Vantagem relacional parcial \\
\hline Baixa centralidade & Alta densidade & Desvantagem relacional parcial \\
\hline Baixa centralidade & Baixa densidade & Desvantagem relacional total \\
\hline
\end{tabular}

Fonte: Elaborado pelas autoras

Ainda em relação ao modelo, é importante salientar que as setas em duplo sentido indicam que não só a responsabilidade social empresarial pode ser disseminada na rede de relações, como também a rede é capaz de influenciar a RSE, de modo que a responsabilidade social pode ou não vir a tornar-se um recurso raro e difícil de imitar 
pelos concorrentes, em função da intensidade de relações sinérgicas desenvolvidas entre a empresa e os atores direta ou indiretamente envolvidos com ela.

\section{Considerações Finais}

Diante do exposto, vislumbra-se a importância da RSE como mecanismo que pode contribuir para o alcance de diferencial competitivo no mercado, na medida em que disseminada na rede de relações "empresa-stakeholders" pode gerar vantagem relacional. Esta, por sua vez, é adquirida a partir da inserção e alinhamento dos princípios da RSE pregados pela empresa com os valores daqueles com os quais mantém relações, ou seja, seus stakeholders, em um fluxo contínuo e constante de relações. Assim, quanto mais intensas e duradouras as relações, maior poderá ser a vantagem de relacionamento.

Como dito em seção anterior, a vantagem relacional decorre da exploração das oportunidades que a empresa pode obter a partir dos relacionamentos que ela desenvolve na rede. Dessa forma, os relacionamentos desenvolvidos entre empresas e stakeholders podem permitir a aquisição de rendas relacionais, as quais correspondem aos ativos tangíveis e intangíveis obtidos por meio do compartilhamento de informações e também da criação do conhecimento de mercado difundido na rede de relacionamentos.

Em termos de relacionamento, o presente estudo baseou-se em algumas premissas:

- Os stakeholders valorizam práticas de responsabilidade social adotadas pelas empresas, principalmente as ações voluntárias;

- Para que a mobilização dos stakeholders, no que se refere à exigência para que as empresas adotem a responsabilidade social, configure-se em ação, é necessário que os stakeholders possuam poder, urgência e recursos para agir, bem como é necessário que fatores externos não impeçam a ação;

- Os relacionamentos podem gerar benefícios para a empresa;

Nessa linha de raciocínio, as empresas podem se beneficiar com os relacionamentos intensos e permeados pela RSE, adquirindo uma vantagem relacional. Por um lado, pode-se identificar a vantagem relacional total. Neste caso, uma empresa central, presente em uma rede densa e permeada pelos princípios da RSE, desenvolve uma relação duradoura e baseada na confiança com seus stakeholders, favorecendo tanto 
a empresa quanto os atores que estão direta ou indiretamente envolvidos com ela. Tal relação pode possibilitar a aquisição de rendas relacionais por parte da empresa, tais como ativos valiosos, raros e difíceis de imitar, os quais podem auxiliar no alcance da vantagem competitiva.

Em outro extremo, uma empresa com baixa centralidade, localizada em uma rede também com baixa densidade, obterá uma desvantagem relacional total. Por não se preocupar em atender as exigências dos stakeholders e se relacionar com outras empresas, tal empresa não consegue desenvolver ativos tangíveis e intangíveis. Essa empresa tentará atuar isoladamente, mas não sobreviverá no ambiente competitivo, uma vez que não existe empresa sem relacionamentos.

A revisão do modelo proposto por Feitosa, Souza e Gómez (2OI4) enriquece o conhecimento das ciências empresariais, contribuindo para a discussão de um novo conceito: vantagem relacional. Esta, se bem gerenciada, pode ajudar as empresas a se manterem vivas no mercado e, inclusive, ser melhores que as concorrentes.

Apesar do caráter inovador do presente estudo, faz-se necessário que sejam efetivados novos estudos que tragam evidências empíricas no que concerne à existência da vantagem relacional, bem como da consequente aquisição de rendas relacionais.

Sugere-se que o teste do modelo leve em conta tanto a percepção de gestores quanto de stakeholders, buscando identificar, dentre outros fatores, quais aspectos são necessários para desenvolver uma relação duradoura e intensa entre ambos, bem como se a RSE é de fato relevante para manter um relacionamento positivo entre a empresa e as partes interessadas.

\section{Referèncias}

ALEJANDRO, V. A.; NORMAN, A. G. Manual introdutório à Análise de Redes Sociais: medidas de centralidade. México: UAEM (Universidad Autonoma Del Estado De Mexico), 2005.

AMIT, R.; SCHOEMAKER, P. J. H. Strategic Assets and Organizational Rent. Strategic Management Journal, v. I4, n. I., p. 33-46, I993.

ÄYVÄRI, A.; MÖLLER, K. Understanding relational and network capabilities - a critical review. 24th IMP conference in Uppsala, Sweden, 2008.

BARNEY, J. Firm Resources and Sustained Competitive Advantage. Journal of Management, v. I7, n. I, p. 99-I2O, I99I. 
BIJMAN, J. Governance structures in Dutch fresh-produce industry. In: C.J.M. ONDERSTEIJN, J.H.M.; WIJNANDS, R.B.M. HUIRNE; KOOTEN, O. V, eds. Quantifying the agri-food supply chain. The Netherlands: Springer, 2006.

BHATTACHARYA, C. B.; KORSCHUN, D.; SEN, S. Strengthening Stakeholder-Company Relationships through Mutually Beneficial Corporate Social Responsibility Initiatives. Journal of Business Ethics, v. 85, n. 2, p. 257 - 272, 2009,

CAO, M.; ZHANG, Q. Supply chain collaborative advantage: A firm’s perspective. International Journal of Production Economics, v.128, p. 358-367, 2010.

CASTELO BRANCO., M.; RODRIGUES, L. L. Corporate social responsibility and resource-based perspectives. Journal of Business Ethics, v.69, n. 2, p. III-I32, 2006.

CHEN, X.; MOORE, K.; RENAUD, L.; DUBÉ, L. From Corporate Social Responsibility to Social Alliances : A Case of Childhood Obesity Prevention. In: RENAUD, L. Les Médias et le Façonnement des Normes en Matière de Santé. Presses de l’Université du Québec, Quebec, 2007.

COHEN, W. M.; LEVINTHAL, D. A. Absorptive Capacity: A New Perspective on Learning and Innovation. Administrative Science Quarterly, v. 35, n. I, p. I28-I52, I990.

COMMISSION OF THE EUROPEAN COMMUNITIES. Corporate Social Responsibility - $A$ Business Contribution to Sustainable Development (Office for Official Publications of the European Communities, Luxemburg), p.I-24., 2002.

COX, M.; MELO, P. T. N. B.; RÉGIS, H. P. Posições centrais em uma rede social. Gestão Contemporânea, Porto Alegre, v.6, n.6, p. 69-96, 2009.

DARNALL, N.; HENRIQUES, I.; SADORSKY, P. Adopting Proactive Environmental Strategy: The Influence of Stakeholders and Firm Size. Journal of Management Studies, v.47, n.6, 2 оIо.

DING, XH.; HUANG, RH. Effects of knowledge spillover on interorganizational resource sharing decision in collaborative knowledge creation. European Journal of Operations Research, v. 2OI, n. O3, 949-959, 2 OIO.

DOZ, Y. L. The evolution of cooperation in strategic alliances: initial conditions or learning processes?. Strategic Management Journal, v. I7, p.55-83, 1996.

DYER, J. H. Specialized Supplier Networks as a Source of Competitive Advantage: Evidence from de Auto Industry. Strategic management Journal, v. I7, n. 4, p. 27I-29I, 1996.

.; SINGH, H. Cooperative Strategy and Sources of Interorganizational Competitive Advantage. The Academy of Management Review, v.23, n.4, p. 660-679, 1998.

;_______; KALE, P. Splitting the Pie: Rent Distribution in Alliances and Networks. Managerial and Decision Economics, v. 29, p. I37-I48, 2008.

FEITOSA, M. J. S.; SOUZA, N. M. O.; GÓMEZ, C. R. P. Princípios da Responsabilidade Social Empresarial nas Relações "Empresa-Stakeholders" como Fonte de Vantagem Competitiva. Revista de Administração, Contabilidade e Sustentabilidade (REUNIR). v. 4, n n I, p. 42-6I, 2014.

FIGUEIREDO, P. N. Aprendizagem tecnológica e inovação industrial em economias emergentes: uma breve contribuição para o desenho e implementação de estudos empíricos e estratégias no Brasil. Revista brasileira de inovação, São Paulo: Fundação Getulio Vargas, v.3, n.2, p. 323-36I, jul./dez. 2004 . 
. Capacidade Tecnológica e Inovação em Organizações de Serviços Intensivos em Conhecimento: evidências de institutos de pesquisa em Tecnologias da Informação e da Comunicação (TICs) no Brasil. Revista brasileira de inovação, São Paulo: Fundação Getulio Vargas, v.5, n.2, p. 403-454, jul./dez. 2006.

FREEMAN, L. C.. Centrality in social networks: conceptual clarification. Social Networks, n. I, p. 2I5-239, I979.

FURTADO, A. Capacitação tecnológica, competitividade e política industrial: uma abordagem setorial e por empresas líderes. São Paulo: IPEA, I33 p., I994.

GILSING, V.; NOOTEBOOM, B.; VANHAVERBEKE, W.; DUYSTERS, G. Network embeddedness and the exploration of novel technologies: technological distance, betweenness centrality and density. Research Policy, v. 37, n.IO, p. I7I7-I73I, 2008.

GRANOVETTER, M. Economic action and social structure: the problem of embeddedness. American Journal of Sociology, v. 9I, n. 3, p. 48I-5IO, I985.

GRANT, R. M. The resource - based theory of competitive advantage: Implications for strategy formulation. California Management Review, v. 33, n. 3, p. II4-I35, Spring, I99I.

. Prospering in Dynamically-Competitive Environments: Organizational Capability as Knowledge Integration. Organization Science, v. 7, n. 4, p. 375-387, , 996.

HAMANN, R. Corporate social responsibility, partnerships, and institutional change: The case of mining companies in South Africa. Natural Resources Forum, v. 28, p. 278-290, 2004.

INSTITUTO ETHOS DE EMPRESAS E RESPOSANBILIDADE SOCIAL. Critérios essenciais de Responsabilidade Social Empresarial e seus Mecanismos de Indução. 2oıo. Disponível em: $<$ http://www.ethos.org.br/_Uniethos/Documents/criterios_essenciais_web.pdf $>$. Acesso em: 20 de Janeiro de 2012.

KOGUT, B. Joint Ventures: Theoretical and empirical Perspectives. Strategic Management Journal, v. 9, p. 319-332, I988.

LARSON, A. Network Dyads in Entrepreneurial Settings: A Study of the Governance of ExchangeRelationships. Administrative Science Quarterly, v. 37, n. I, p. 76-IO4, I992.

LEANDRO, A. RABELO, T. A responsabilidade social das empresas: incursão ao conceito e suas relações com a cultura organizacional. Comunicação nas Organizações (exedra), número especial, p. II- 39,2 OII.

MACAULAY, N. Non-contractual relations in business: a preliminary study. American sociological review, v. $28, \mathrm{n}$. I, I963.

MADHOK, A. Cost, value and foreign market entry mode: the transaction and the firm. Strategic Management Journal, v. I8, p. 39-6I, I997.

MARTELETO, R. M. Análise de redes sociais: aplicação nos estudos de transferência da informação. Revista Ciência da Informação, v. 3O, n. I, p. 7I-8I, $200 \mathrm{I}$.

MARTINS, M. E.; CSILLAG, J. M.; PEREIRA, S. C. F.. A produção e a colaboração científica em operações de serviços: uma análise da rede internacional de pesquisadores e instituições. In: XII SIMPÓSIO DE ADMINISTRAÇÃO DA PRODUÇÃO, LOGÍSTICA E OPERAÇÕES INTERNACIONAIS, São Paulo, 2009. Anais... São Paulo, p.I-I7, 2OO9. 
MASQUIETTO, C. D.; SACOMANO NETO, M.; GIULIANI, A. C. Centralidade e Densidade em Redes de Empresas: Um Estudo no Arranjo Produtivo Local do Álcool. Anais: VIEGEPE, 20 oIO.

MIRON, D.; PECTU, M.; SOBOLEVSCHI, I. M. Corporate social responsibility and the sustainable competitive advantage. $A E-$ Amfiteatru Economic, v. I3, n. 29, p.I62-I79, 2 OII.

MITCHEL, R. L.; AGLE, B. R.; WOOD, D. J. 1997. Towards a theory of stakeholder identification and salience deifing the principle of who and what really counts. Academy of Management, v.22, n. 4 , p. $853-886$, I997.

MURSITAMA, T. N. Creating relational rents: The effect of business groups on affiliated firms' performance in Indonesia. Asia Pacific Journal of Management, v. 23, n. 4, p. 537-557, 2006.

PECI, A. Emergência e proliferação de redes organizacionais: marcando mudanças no mundo de negócios. Revista de Administração Pública, Rio de Janeiro, v. 33, n. 6, p. 7-24,I999.

PENROSE, E. T. A teoria do crescimento da firma. Editora da Unicamp, São Paulo, 2009.

PORTER, M. E. Estratégia competitiva: Técnicas para análise de indústrias e da concorrência. Rio de Janeiro. Campus, 1986.

RAMACHANDRAN, V. Strategic Corporate Social Responsibility: A 'Dynamic Capabilities’ Perspective. Corporate Social Responsibility and Environmental Management, v. I8, p. 285-293, 2 OIO.

ROSSONI, L.; GUARIDO FILHO, E. R. Cooperação interinstitucional no campo da pesquisa em estratégia. Revista de Administração de Empresas, v. 47, n. 4, p.72-86, 2007.

ROWLEY, T. J. Moving beyond Dyadic Ties: A Network Theory of Stakeholder Influences. The Academy of Management Review, v. 22, n. 4, p. 887-9IO, 1997 .

.; MOLDOVEANU, M. When Will Stakeholder Groups Act? An Interest- and Identity-Based Model of StakeholderGroup Mobilization. The Academy of Management Review, v. 28, n. 2, p. 204219, 2003 .

SACHDEVA, A.; PANFIL, O. CSR Perceptions and Activities of Small and Medium Enterprises (SMEs) in Seven Geographical Clusters - Survey Report, UNIDO, Vienna, 2008.

SOUZA, N. M. O. ; PRIMO, M. A. M.; CORREA, A. P. M. Impacto das organizações de serviços intensivos em conhecimento na capacitação tecnológica das empresas do arranjo produtivo local do porto digital. In: Anais... XIV SIMPÓSIO DE ADMINISTRAÇÃO DA PRODUÇÃO, LOGÍSTICA E OPERAÇÕES INTERNACIONAIS, 2OII, SÃO PAULO. XIV SIMPOI, $20 I I$.

SILVA, C. L. M.; COSER, C. Rede de Relaçőes Interorganizacionais no Campo Organizacional de Videira-SC. Revista de Administração Contemporânea, v. IO, n. 4, 2006.

SOUZA, Q. R.; QUANDT, C. O. Governança de redes interorganizacionais e níveis de controle formal: atividades de gestão do conhecimento em uma rede do terceiro setor. Revista Alcance, Paraná, vl. I4, n.2., p. 207-23O, 2007.

TOMAÉL, M. I.; MARTELETO, R. M. Redes Sociais: Posições dos atores no fluxo da informação. Encontros Bibli: revista eletrônica em Ciência da Informação, edição especial, p. 75-9I, 2006.

TROCCOLI, I. R.; MACEDO-SOARES, T. D. L. v. A. Análise Estratégica sob Ótica Relacional: Enfocando Grupos e Blocos Estratégicos. Revista de Administração Contemporânea, v. 8, n. I, p. 55782004 . 
VACHON, S., KLASSEN, R.D. Environmental management and manufacturing performance: The role of collaboration in the supply chain. International Journal of Production Economics, v. III, n. 2, p. 299-3I5, 2008.

WASSERMAN, S.; FAUST, K.. Social network analysis: methods and applications. Cambridge: Cambridge University Press. 8:857 p, I994.

WERNERFELT, B. A resource-based view of the firm. Strategic Management Journal, v. 5, p. I7I-I80, I984.

WILLIAMSON, o. E. Transaction-Cost Economics: The Governance of Contractual Relations. Journal of Law and Economics, v. 22, n. 2, p. 233-26I, I979. . The economic institutions of capitalism. New York: Free Press, 1985.

. Comparative economic organization: The analysis of discrete structure alternative, Administrative Science Quarterly, v.36, n. 2, p. 269-296, I99I.

ZADEK, S.; SABAPATHY, J.; DØSSING, H.; SWIFT, T. Agrupamentos de Responsabilidade Corporativa: Alavancando a Responsabilidade Corporativa para Atingir Benefícios Competitivos Nacionais. Reflexão, São Paulo, n. 9, 2003. Disponível em :

$<$ http://wwwI.ethos.org.br/EthosWeb/arquivo/o-A-629reflexao\%2009.pdf $>$. Acesso em 2I de janeiro de 2012. 